\title{
Evaluation of Filamentous Fungi and Inducers for the Production of Endo-Polygalacturonase by Solid State Fermentation
}

\begin{abstract}
Adriana B. Dartora ${ }^{\mathrm{a}, \mathrm{b}}$, Telma E. Bertolin ${ }^{\mathrm{a}, *}$, Denise Bilibio ${ }^{\mathrm{a}}$, Mauricio M. Silveira ${ }^{\mathrm{b}}$ and Jorge A. V. Costa

a Centro de Pesquisa em Alimentação, Universidade de Passo Fundo, Caixa Postal 611, 99070-010 - Passo Fundo, RS, Brazil. Fax: +55543168455. E-mail: telma@upf.tche.br

b Instituto de Biotecnologia, Universidade de Caxias do Sul, Caxias do Sul, RS, Brazil

c Departamento de Química, Fundação Universidade Federal do Rio Grande, Rio Grande, RS, Brazil

* Author for correspondence and reprint requests

Z. Naturforsch. 57c, 666-670 (2002); received February 28/April 11, 2002

Pectinase, Endo-polygalacturonase, Solid State Fermentation

Five strains of filamentous fungi (Aspergillus niger strains NRRL 3122 and T0005007-2, Aspergillus oryzae CCT 3940, Aspergillus awamori NRRL 3112 and a Trichoderma sp.) were compared for their capacity to produce endo-polygalacturonase (endo-PG) in solid state fermentation. Maximum pectinolytic activity was reached in $72 \mathrm{~h}$ of growth, the best two fungal strains being $A$. niger T0005007-2 and A. oryzae CCT 3940. Three types of commercial purified pectin and four of unprocessed pectin (tangerine, orange, Tahiti lime and sweet lime rind) were used to assess the effect of pectin on the production of endo-PG by A. niger T0005007-2. Maximum pectinolytic activity was achieved using 6 and $10 \%(\mathrm{w} / \mathrm{w})$ of purified pectin as inducer. Depending on the origin of the commercial pectin used as inducer, maximum endo-PG levels varied from 223 to 876 units per gram of dry medium (one endo-PG unit (U) was defined as the quantity of enzyme which caused a reduction in viscosity of $50 \%$ in a $1 \% \mathrm{w} / \mathrm{v}$ solution of pectin in $30 \mathrm{~min}$ ), indicating that care should be taken when choosing this component of the medium. When the crude pectins were used as inducers at the same concentration as purified pectin, maximum endo-PG activities were $250-300$ units/g. However, by increasing the amount of Tahiti lime rind to $50 \%(\mathrm{w} / \mathrm{w})$ maximum endo-PG was 919 $\mathrm{U} / \mathrm{g}$, thus opening up the possibility of a low cost medium for endo-PG production.
\end{abstract}

\section{Introduction}

Pectinases are a group of enzymes that attack and de-polymerize pectin by hydrolysis and transelimination as well as by de-esterification reactions which hydrolyze the ester bond between the carboxyl and methyl of groups pectin (Ceci and Lozano, 1998).

Various genera of microorganisms can produce pectinase, but the filamentous fungi Aspergillus niger is most used because it is classified as 'generally regarded as safe' (GRAS) by the United States Food and Drugs Administration (USFDA), which has approved its use in the food industry (Pariza and Foster, 1983). Other fungi, such as Aspergillus oryzae (Ueda et al., 1982), Thermoascus aurantiacus (Martins et al., 2002) and Penicillium expansum (Alkorta et al., 1998; FernandesSalomão et al., 1996) are also sometimes used.

Preparations of pectinolytic enzymes have many industrial applications, but are mainly used in the food industry in operations like clarification of fruit juices and wines and the extraction of vegetable oils (Whitaker, 1994; Demir et al., 2001). In the textile industry pectinases are sometimes used in the treatment of natural fibers, such as linen and ramie fibers (Baracat et al., 1991).

Solid state fermentation is generally defined as the cultivation of microorganisms on solid materials in the absence or near-absence of free water (Sanzo et al., 2001). This process has several advantages, including the ability to reach high product concentrations and the production of less liquid effluents, although the control of $\mathrm{pH}$, temperature and oxygen tension can be difficult (Cannel and Moo-Young, 1980; Costa et al., 1998; Castilho et al., 2000). Pectinase production by Aspergillus strains has been observed to be higher in solid state fermentation than in submerged process (Solis-Pereira et al., 1996; Maldonado et al., 1998). Acuña-Arguelles et al. (1995) have reported that $A$. niger produces distinct physiological re- 
sponses depending on the fermentation technique used, and that there are advantages to the production of pectinase using solid state processes as compared to submersed processes.

The synthesis of pectinase is induced or stimulated by the presence of pectin, and for economic reasons this is normally supplied by adding sugar beet or apple bagasse or citrus fruit rind and wheat bran to the culture medium (Rombouts and Pilnik, 1980). This paper describes the selection of a fungus with a good capacity for the production of endo-polygalacturonase (endo-PG), a pectinolytic enzyme that hydrolyzes the internal $\alpha(1 \rightarrow 4)$ linkage between D-galacturonic acid units of pectin, and compares the effect of different types and concentrations of pectin as inducers in solid state fermentation.

\section{Materials and Methods}

\section{Microorganisms}

The five filamentous fungi assessed were: Aspergillus oryzae CCT 3940 (Universidade Estadual de Campinas, Brazil), Aspergillus niger NRRL 3122, A. niger T0005007-2 (Universidad de Salta, Argentina), Aspergillus awamori NRRL 3112 and a strain of Trichoderma $s p$ isolated by our group, all of which were maintained on potato-dextrose agar (PDA) and replicated monthly.

\section{Media}

Wheat bran (Moinho Santa Lúcia, Passo Fundo, Brazil) was used as the support and main carbon source for all media, to which was added $45 \mathrm{ml}$ of a mineral salts (MS) solution containing (\% w/v) $\mathrm{KH}_{2} \mathrm{PO}_{4}, 0.2 ; \mathrm{MgSO}_{4}, 0.1 ;\left(\mathrm{NH}_{4}\right)_{2} \mathrm{SO}_{4}, 0.4 ; \mathrm{FeSO}_{4}$, $6.3 \times 10^{-4} ; \mathrm{MnSO}_{4}, 1.0 \times 10^{-4}$ and $\mathrm{ZnSO}_{4}, 6.2 \times$ $10^{-4}$ for each $100 \mathrm{~g}$ of bran (Bertolin et al., 2001), to produce basic wheat bran medium (WB). Purified or unprocessed pectin were added to WB medium to serve as pectinase inducer, as detailed below. The initial moisture of all media was adjusted to $63 \%$ by the addition of distilled water. All media were autoclaved at $121{ }^{\circ} \mathrm{C}$ for $30 \mathrm{~min}$.

For strain selection experiments, all the above strains were grown in WB medium enriched with $6 \%(w / w)$ of apple pectin (SIGMA, St. Louis, USA) (Dartora et al., 2000). Further assays were conducted with this medium, with the selected strain A. niger T0005007-2, to evaluate the best way to prepare the culture media: Method 1 - apple pectin was mixed with $\mathrm{WB}$, the MS solution added, the moisture adjusted with distilled water and the media sterilized; Method 2 - apple pectin was added to the MS solution and this and the WB media sterilized separately, the moisture being adjusted after autoclaving using sterilized distilled water; Method 3 - The MS solution was added to the WB along with half the quantity of distilled water needed to adjust the moisture, the apple pectin scattered over the humid media and the remaining distilled water added before sterilization.

Aspergillus niger strain T0005007-2 was also used in experiments with purified and unprocessed pectins. To assess purified pectinase inducers, we used SIGMA apple pectin and two types of citrus pectin produced in Brazil, citrus pectin A (INLAB, São Paulo, Brazil) and citrus pectin B (DELAWARE, Porto Alegre, Brazil) added to WB media at concentrations of 2, 4, 6, 8 and $10 \%(\mathrm{w} / \mathrm{w})$. To assess unprocessed inducers we used the dried and ground rind from tangerine (Citrus deliciosa Tenore), orange (Citrus sinensis Osbeck), Tahiti lime (Citrus latifolia Tanaka) and sweet lime (Citrus limettioides Tanaka) added to WB media at concentrations of 2, 4, 6, 8, 10\% (w/w). C. latifolia based medium was also prepared with 30,40 and $50 \%(\mathrm{w} / \mathrm{w})$ rind.

\section{Preparation of spore suspension}

For each fungi, $50 \mathrm{ml}$ of PDA was placed in $1000 \mathrm{ml}$ flasks and inoculated by adding $0.2 \mathrm{ml}$ of spore suspension produced by adding $10 \mathrm{ml}$ of water to PDA slants of the appropriate fungi. The flasks were incubated at $30^{\circ} \mathrm{C}$ for 5 days. The spore suspension was obtained using sterile water and adjusted to $1 \times 10^{7}$ spores $/ \mathrm{ml}$.

\section{Culture conditions}

The experiments were carried out in $250 \mathrm{ml}$ flasks each containing $14 \mathrm{~g}$ of WB medium which itself contained different types and quantities of pectin as inducer. Controls contained no pectin. The flasks were inoculated with $1 \mathrm{ml}$ of spore suspension $\left(1 \times 10^{7}\right.$ spores $\left./ \mathrm{ml}\right)$. This procedure was repeated for each of the fungi. The flasks were statically incubated at $30{ }^{\circ} \mathrm{C}$ in a humidified atmosphere. For each sample point - after 0, 14, 24, 40, 
$48,63,72$ and $96 \mathrm{~h}$ of cultivation - two flasks were removed and analyzed.

\section{Analytical methods}

Moisture of culture media was determined according to A.O.A.C. (1997). For quantification of the total carbohydrate (TC) content in the different media, the samples were hydrolyzed with concentrated HCI in an autoclave at $121^{\circ} \mathrm{C}$ for $15 \mathrm{~min}$, alkalinized to $\mathrm{pH} 14$ with $40 \%$ (w/v) $\mathrm{NaOH}$ and treated with potassium ferricyanide and cupric sulfate solutions to remove proteins, after which the concentration of soluble carbohydrate was estimated by the 3,5 dinitrosalicilic acid (DNS) method (Miller, 1959) as total reducing sugars. Soluble carbohydrate (SC) present in the culture media was measured as free reducing sugars by the DNS method without prior hydrolysis of the samples. Both TC and SC in this paper are expressed as $\mathrm{mg}$ of reducing sugars per $\mathrm{g}$ of dry medium.

Endo-PG was extracted from the media by suspending $1 \mathrm{~g}$ of dry sample in $15 \mathrm{ml}$ of sodium acetate buffer ( $\mathrm{pH} 4.0$ ) contained in $125 \mathrm{ml}$ flasks agitated at $100 \mathrm{rev} / \mathrm{min}$, the crude enzyme solution being filtered through Whatman no. 41 filterpaper. The endo-PG activity of the filtrate was determined by adding $2 \mathrm{ml}$ of filtrate to $8 \mathrm{ml}$ of a $1 \%$ (w/v) apple pectin (SIGMA, USA) solution and measuring the viscosity in a RVDV-II viscometer (Brookfield Engineering, Middleboro, USA). One endo-PG unit (U) was defined as the quantity of enzyme which caused a reduction in viscosity of $50 \%$ in $30 \mathrm{~min}$ of reaction under standard conditions (Gainvors et al., 2000). Endo-PG activity in this work is expressed as units per gram of dry medium $(\mathrm{U} / \mathrm{g})$.

\section{Results and Discussion}

\section{Selection of fungi strain with highest endo-PG production}

Figure 1 shows the time course of total carbohydrate (TC) and soluble carbohydrate (SC) concentrations, both measured as reducing sugars, and endo-polygalacturonase activity (endo-PG), during the cultivation of different fungi on WB medium with $6 \%(\mathrm{w} / \mathrm{w})$ SIGMA apple pectin. In general, the TC level decreased until it reached a plateau at which there was a relatively high concentration of carbohydrate still available to the fungi. This unused carbohydrate may have resulted, probably, from the fact that mycelial growth occurred predominantly on the surface of the solid medium and the fungal mycelia may not have extend far into the medium due to the limitation of oxygen. Additionally, some other fact could be involved, such as limitation of another nutrient, change in $\mathrm{pH}$ or production of a toxic metabolite.

With respect to the variation in the concentration of soluble carbohydrate (SC) with time, from Fig. 1, one can see that there was an accumulation of reducing sugars in the medium during the initial phase of cultivation which varied according to the fungal strain, probably because at this stage the rate of starch hydrolysis was greater than the rate of sugar consumption. After SC levels reached their maximum values the level dropped, agreeing with previous work by Cavalitto et al. (1996). The peak SC values for $A$. niger T0005007-2 and $A$. oryzae were lower than those of the other fungi, which may have been due to the relatively low production of amyloglycosidase by these two fungi. Although A. awamori had the highest SC production rate in the early stages of the experiment it was not an efficient producer of endo-PG.

Figure 1 also shows that maximum enzymatic activity occurred at about $72 \mathrm{~h}$, the highest endoPG activities being produced by $A$. niger T0005007-2 and $A$. oryzae. Working with the same media components as was used in our study, but using submerged culture, Malvessi (2000) found high endo-PG activities with $A$. oryzae CCT3940 but insignificant titers of these enzymes with A. niger T0005007-2, showing the difficulty involved in comparing submerse and solid-state enzyme production. We decided to use $A$. niger T00050072 for the inducer evaluation experiments using different types of pectin because $A$. niger strains are generally regarded as safe by the USFDA.

\section{Assessment of inducers using A. niger T0005007-2}

The way the media was prepared influenced the results of the process and it is probable that such an effect would be even more important on an industrial scale. After $72 \mathrm{~h}$ of solid state culture of A. niger T0005007-2 in 6\% (w/w) SIGMA apple 


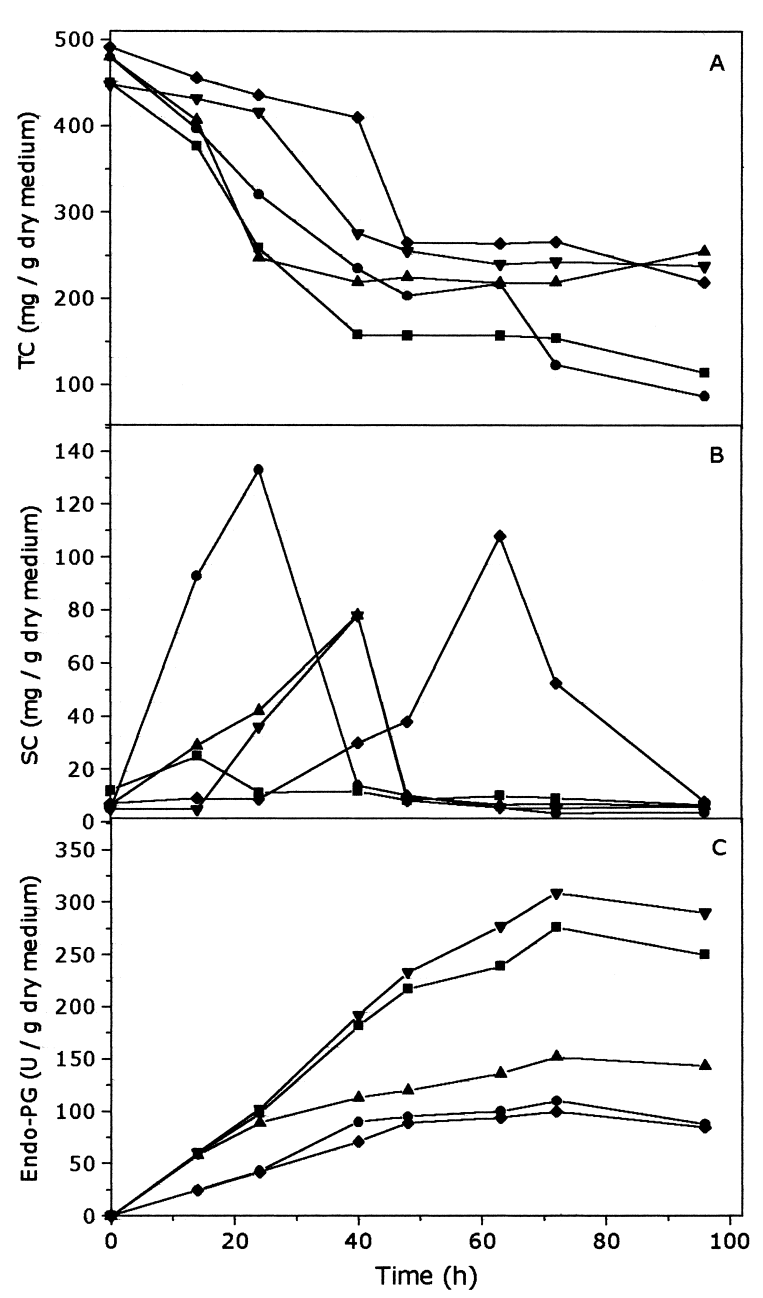

Fig. 1. Variation in the concentrations of total carbohydrate (TC) $[\mathrm{A}]$ and soluble carbohydrate (SC) [B], and in endo-polygalacturonase (endo-PG) activity [C] with time during the cultivation of different filamentous fungi in $6 \%(\mathrm{w} / \mathrm{w})$ SIGMA apple pectin medium. (A) Aspergillus niger ATCC 3122; (O) A. awamori NRRL 3112; (口); A. oryzae CCT 3940; ( $)$ A. niger T0005007-2; Trichoderma $s p$.

pectin medium prepared by the three different methods proposed, the following maximum endoPG activities were achieved: Method 1, $328 \mathrm{U} / \mathrm{g}$; Method 2, $219 \mathrm{U} / \mathrm{g}$; Method 3, $760 \mathrm{U} / \mathrm{g}$. It appears that the most important factor in media preparation is the homogenous distribution of the inducer, which should be distributed in such a way as to avoid the formation of lumps which may limit oxygen diffusion and produce regions where there are insufficient concentrations of pectin to initiate endo-PG production.

The effect of different types and concentrations of inducers on endo-PG production by $A$. niger T0005007-2 was evaluated after $72 \mathrm{~h}$ of cultivation, when the maximum endo-PG value was reached. For any commercial pectin tested, the maximum activities were achieved with WB medium containing $6-10 \%(\mathrm{w} / \mathrm{w})$ inducer. The highest endo-PG value, over $850 \mathrm{U} / \mathrm{g}$, was obtained with SIGMA apple pectin, while medium containing commercial citrus pectin A also presented good results with a maximum activity of just under $700 \mathrm{U} / \mathrm{g}$. The commercial pectin B presented lower enzyme activity $(233 \mathrm{U} / \mathrm{g})$, with results similar to, or lower than, those seen with unprocessed pectin. This variation in endo-PG production is perhaps due to the fact that pectins are polysaccharides of very variable structure, being made up of different monomers with various types of ramification and levels of esterification (Ceci and Lozano, 1998). These results indicate that care must be taken to the choice of commercial pectin used as endo-PG inducer.

WB medium containing $8-10 \%(\mathrm{w} / \mathrm{w})$ of Tahiti lime, orange or tangerine rind produced maximum endo-PG activities of 250-300 U/g, whereas the same amount of sweet lime rind led to a maximum endo-PG activity of only $180 \mathrm{U} / \mathrm{g}$. In addition to the reasons discussed in relation to purified pectins, the lower endo PG obtained with unprocessed inducers may have been related to content of pectin present in these materials, which in the case of orange and Tahiti lime rinds is only about 30\% (Rombouts and Pilnik, 1996). Ceci and Lozano (1998) have also pointed out that it is also possible that the low purity of such pectin sources makes it difficult for a microorganism to gain access to the inducer, resulting in lower pectinase production.

Further experiments were carried out using WB medium containing 10, 30, 40 and $50 \%$ (w/w) Tahiti lime rind. The maximum endo-PG activities, after $72 \mathrm{~h}$ of solid state culture of $A$. niger T0005007-2, were 275, 475, 755, and $919 \mathrm{U} / \mathrm{g}$, respectively. These results indicate that Tahiti lime rind can be used as an effective inducer for the production of endo-PG by this fungus, since the highest pectinolytic activity was comparable to, or higher than, that obtained using purified pectin. 
As no significant difference was observed in endoPG production in medium containing between 6 and $10 \%(w / w)$ Tahiti lime rind, the data for these last group of experiments appear to be somewhat contradictory. Probably this may have been due to the small difference $(4 \%)$ between the concentration of inducer in the first set of runs and from the relatively low pectin content of this material (about 30\%). The fact remains that $A$. niger produced over $900 \mathrm{U} / \mathrm{g}$ of endo-PG in medium containing $50 \%(\mathrm{w} / \mathrm{w})$ Tahiti lime rind, demonstrating that it is possible to formulate a low-cost medium for the production of endo-polygalacturonase by solid state fermentation.
Acuña-Argüelles M. E., Gutiérrez-Rojas M., ViniegraGonzález G and Favela-Torres E. (1995), Production and properties of three pectinolytic activities produced by Aspergillus niger in submerged and solidstate fermentation. Appl. Microbiol. Biotechnol. 48, $808-814$.

Alkorta I., Garbisu C., Llama M. J. and Serra J. L. (1998), Industrial applications of pectic enzymes: a review. Process Biochem. 33, 21-28.

Association of Official Analytical Chemists A. O. A.C. (1997), Official Methods of Analysis. 16th ed. Arlington VA., USA.

Baracat M. C., Vanetti M. C. D., Araújo E. F. and Silva D. O. (1991), Growth conditions of a pectinolytic Aspergillus fumigatus for degumming of natural fibres. Biotechnol. Lett. 13, 693-696.

Bertolin T. E., Costa J. A. V. and Pasquali G. D. (2001) Glucoamylase production in batch and fed-batch solid state fermentation: effect of maltose and starch addition. J. Microbiol. Biotechnol. 11, 13-16.

Cannel E. and Moo-Young M. (1980), Solid state fermentation systems. Process Biochem. 15, 2-7.

Castilho L. R., Medronho R. A. and Alves T. L. M. (2000), Production and extraction of pectinases obtained by solid state fermentation of agroindustrial residues with Aspergillus niger. Bioresource Technol. 71, 45-50.

Cavalitto F. S., Arcas J. A. and Hours R. A. (1996), Pectinase production profile of Aspergillus foetidus in solid - state cultures at different acidities. Biotechnol. Lett. 18, 251-156.

Ceci L. and Lozano J. (1998), Determination of enzymatic activities of commercial pectinases for the clarification of apple juice. Food Chem. 61, 237- 241.

Costa J. A. V., Alegre R. M. and Hasan S. D. M. (1998), Packing density and thermal conductivity determination for rice bran solid state fermentation. Biotechnol. Tech. 12, 747-750.

Dartora A. B., Bertolin T. E., Bilibio D., Silveira M. M. and Costa J. A. V. (2000), Estudo comparativo de indutores na produção de pectinases por Aspergillus niger em cultivo semi-sólido. In: Annals of the XIII Simpósio Nacional de Fermentações, Teresópolis, Brazil.

Demir N., Acar J., Sarioglu K. and Mutlu M. (2001), The use of commercial pectinase in fruit juice industry. part 3: immobilized pectinase for mash treatment. J. Food Eng. 47, 275-280.
Fernandes-Salomão T. M., Amorin A. C. R., ChavesAlves V. M., Coelho J. L. C., Silva D. O. and Araújo E. L. (1996), Isolation of pectinase hyperproducing mutants of Penicillium expansum. Rev. Microbiol., 27, $15-18$.

Gainvors A., Nedjaoum N., Gognies S., Muzart M., Nedjma M. and Belarbi A. (2000), Purification and characterization of acidic endo-polygalacturonase encoded by the PGL1-1 gene from Saccharomyces cerevisiae. FEMS Microbiol. Lett. 183, 131-135.

Maldonado M. C. and Strasser De Saad A. M. (1998), Production of pectinesterase and polygalactruronase by Aspergillus niger in submerged and solid state systems. J. Ind. Microbiol. Biotechnol. 20, 34-38.

Malvessi E. (2000), Estudo de produção de poligalacturonases por Aspergillus oryzae em processo submerso. MSc. Thesis. Universidade de Caxias do Sul, Brazil.

Martins E. S., Silva D., Silva R. and Gomes E. (2002), Solid state production of thermostable pectinases from thermophilic Thermoascus aurantiacus. Process Biochem. 37, 949-954.

Miller G. L. (1959), Use of dinitrosalicylic acid reagent for determination of reducing sugar. Anal. Chem. 31, 426-428.

Pariza M. W. and Foster E. M. (1983), Determining the safety of enzymes used in food processing. J. Food Prot. 46, 453-458.

Roumbouts F. M. and Pilnik W. (1980), Pectic enzymes. In: Economic Microbiology (Rose A. H., ed.). Academic Press, London, Vol. 5, pp. 227-282.

Sanzo A. V., Hasan S. D. M., Costa J. A. V. and Bertolin T. E. (2001), Enhanced glucoamylase production in semi-continuous solid state cultivation of Aspergillus niger NRRL 3122. Ciência \& Engenharia, 10, 59-62.

Solis-Pereyra S., Favela-Torres E., Gutiérrez-Rojas M., Roussos S., Saucedo-Castañeda G., and ViniegraGonzáles G. (1996), Production of pectinases by Aspergillus niger in solid state fermentation at high initial glucose concentrations. World J. Microbiol. Biotechnol. 12, 257-260.

Ueda S., Fujio Y. and Lim J. Y. (1982), Production and some properties of pectic enzymes from Aspergillus oryzae A-3. J. Appl. Biochem. 4, 524-532.

Whitaker J. R. (1994), Pectin substances, pectic enzymes and haze formation in fruit juices. Enzyme Microbiol. Technol. 6, 341-349. 